\title{
Concepções sobre desenvolvimento infantil na perspectiva de educadoras em creches públicas e particulares
}

\author{
Ellis Regina Ferreira dos Santos $i$ \\ Instituto Federal de Educação, Ciência e Tecnologia da Paraíba, Brasil \\ Deborah Dornellas Ramosii \\ Universidade Federal de Alagoas, Brasil \\ Nádia Maria Ribeiro Salomãoiii \\ Universidade Federal da Paraíba, Brasil
}

\begin{abstract}
Resumo
Neste estudo, objetivou-se investigar as concepções de educadoras de creches públicas e particulares sobre desenvolvimento infantil. Desse modo, aplicou-se uma entrevista semiestruturada a 24 educadoras. Os dados foram analisados a partir da técnica de análise de conteúdo categorial temática. De modo geral, verificou-se que, em relação às concepções sobre desenvolvimento infantil, predominou, nos dois grupos de educadoras, a subcategoria Desenvolvimento por estágios. Essas educadoras destacaram o Ambiente sociofamiliar desestruturado e o Despreparo do educador como sendo os principais aspectos desfavoráveis à promoção do desenvolvimento infantil e caracterizaram o desenvolvimento das crianças, quando inseridas na rotina da creche, como sendo positivo. Almeja-se, com este estudo, oferecer subsídios para o planejamento de intervenções com vistas a promover 0 desenvolvimento infantil.
\end{abstract}

Palavras-chave

Concepções; Desenvolvimento infantil; Educadoras; Creches públicas e particulares 


\section{Introdução}

Ao estudar como os adultos concebem o desenvolvimento das crianças, faz-se essencial destacar a relevância das concepções vigentes na cultura sobre o desenvolvimento infantil e, mais especificamente, entre os educadores responsáveis por estruturar e possibilitar o cuidado à criança.

Desse modo, o presente trabalho objetivou investigar as concepções de educadoras em creches públicas e particulares sobre o desenvolvimento infantil, considerando o entendimento de que o estudo das concepções de infância configura-se como um fator crucial para a compreensão das práticas educativas do adulto em relação à socialização da criança e à promoção do seu desenvolvimento. Essas concepções de infância são oriundas das ideias e crenças sociais que os adultos adquirem através das suas experiências socioculturais sobre o desenvolvimento.

Neste estudo, compreende-se o desenvolvimento humano como resultante de um processo dialógico, dinâmico, histórico e cultural, que prepara o indivíduo, através das trocas sociais, para novas formas de conhecimento. Para tanto, consideram-se as contribuições oriundas da teoria sócio-histórica de Vigotski (2007), que defende uma compreensão do humano enquanto um ser ativo, cujo desenvolvimento é constituído, paulatinamente, mediante interações entre aspectos biológicos e, sobretudo, sociais, haja vista que esse processo se configura em um contexto que é histórico e, essencialmente, cultural.

Pondera-se, portanto, que conhecer como o educador de creche concebe o desenvolvimento infantil pode revelar indícios da forma como esse profissional interage com a criança e lida com o seu processo de aprendizado no cotidiano da creche, de forma a promover uma prática educativa que tenha como norte o reconhecimento de que "o aprendizado humano pressupõe uma natureza social específica e um processo através do qual as crianças penetram na vida intelectual daqueles que as cercam" (Vigotski, 2007, p. 100).

\section{Marco teórico-conceitual das concepções sobre desenvolvimento infantil}

Ao pesquisar sobre os sistemas de crenças e suas influências sobre as ações dos pais em relação aos seus filhos, Harkness e Super (1996) 
destacam a importância de considerar o meio cultural como fazendo parte da formação de crenças dos pais e dos adultos em geral. Ou seja, a compreensão dos pais sobre a natureza da criança, a estrutura do desenvolvimento e o significado do comportamento é compartilhada com membros de um grupo cultural. Essa compreensão é desenvolvida no contexto da vida, em um determinado tempo e lugar, e está relacionada com outros aspectos, incluindo a natureza e o significado sobre o que é ser pai/mãe, família e indivíduo em cada sociedade.

De acordo com Goodnow (1996), há quatro razões para considerar as crenças parentais: 1) elas são uma interessante forma de cognição e desenvolvimento do adulto; 2) promovem uma forma de compreender as ações dos pais; 3) as ideias parentais estão inseridas no contexto do desenvolvimento infantil; 4) elas podem promover direções nos processos de transmissão e troca cultural. Através dessas razões, é possível compreender que as ideias e as ações parentais são particularmente relevantes para uma perspectiva cultural de análise das relações entre as crenças e o comportamento no nível cultural.

A partir desse enfoque, Shawalb, Shawalb, e Shoji (1996) consideram que as percepções maternas sobre o temperamento da criança são construções, em grande parte, culturais. Ao descreverem e avaliarem o temperamento de suas crianças, as mães revelam, na verdade, a opinião social sobre a personalidade, a individualidade e a emotividade.

Ao especularem sobre as crenças ou cognições parentais e a sua influência sobre as práticas de cuidado e comportamentos em relação ao desenvolvimento da criança, Seidl-de-Moura et al. (2004) também destacam o papel dos aspectos sociais, culturais e históricos sobre o desenvolvimento humano, levando em conta, nesse contexto, o modelo de nichos de desenvolvimento (Harkness \& Super, 1996), o qual considera que o desenvolvimento infantil se processa em um eixo central configurado pela casa da família e se apresenta composto por três subsistemas: o ambiente físico e social onde a criança vive; os costumes estabelecidos cultural e historicamente, relacionados aos cuidados e à criação das crianças; e a psicologia dos cuidadores. A partir da mediação desses fatores, considera-se que as crenças parentais repercutem sobre as práticas de cuidado, assim como tais práticas influenciam a elaboração dessas crenças, "e práticas e 
crenças transformarão e serão transformadas pelo ambiente físico e social. É nessa dinâmica complexa que se situa o desenvolvimento infantil" (Seidl-deMoura et al., 2004, p. 422).

Além dos estudos sobre as concepções parentais, destaca-se a relevância de se investigar as concepções de outros cuidadores habituais das crianças, tais como os profissionais da educação infantil, visto que debruçarse sobre as concepções desses educadores acerca do desenvolvimento humano consiste em um esforço para compreender a forma pela qual as crenças culturais, os valores coletivos e as teorias vigentes se integram com as práticas desses profissionais e estas com o processo de desenvolvimento dos seus alunos.

Portanto, da mesma forma que os comportamentos parentais não consistem em respostas acidentais em relação ao comportamento dos filhos, mas se constituem a partir das crenças elaboradas através das vivências e experiências sociais e culturais ao longo de suas vidas, pode-se compreender que os educadores de creche, igualmente, agem com as crianças de acordo com as suas ideias e expectativas sobre o desenvolvimento infantil. Nessa premissa, os estudos de Melchiori, Biasoli-Alves, Souza, e Bugliani (2007), Almeida e Dessandre (2008), Jorge, Reis, e Nascimento (2008) e Ramos e Salomão (2013) apresentam, no cerne das suas investigações, a relevância do estudo das concepções de infância dos educadores para se compreender a qualidade das suas práticas na promoção do desenvolvimento das crianças.

Melchiori et al. (2007) realizaram uma pesquisa com 50 mães que tinham filhos de 4 a 24 meses de idade, os quais frequentavam uma creche pertencente a um hospital universitário de uma cidade do interior paulista, e 21 de suas educadoras, que eram responsáveis por 90 bebês dentro dessa referida faixa etária. Pretendia-se analisar as crenças dessas mães a respeito do temperamento e do desempenho infantis e compará-las com as crenças das educadoras. Os resultados encontrados apontaram pouca diferença entre as crenças das mães e das educadoras, verificando também uma predominância de crenças ambientalistas sobre o desempenho e o temperamento dos bebês, sendo que os pais foram considerados pelas entrevistadas como os que mais exerciam influência sobre o desenvolvimento das crianças. Destaca-se que as mães praticamente não reconheciam o papel das educadoras na promoção do desenvolvimento dos seus filhos, e as 
próprias educadoras subestimaram sua influência no desempenho dos bebês. Ressalta-se, ainda, que as profissionais, apesar de valorizarem o papel do pai e da mãe, em particular, no desenvolvimento dos bebês, tendem a considerar a influência materna como negativa.

Considerando a relevância do estudo sobre as concepções para a promoção do desenvolvimento, Almeida e Dessandre (2008) entrevistaram 23 professoras de Unidades de Educação Infantil sobre suas crenças e valores acerca da educação infantil, buscando analisar as práticas dessas referidas professoras e suas relações com a promoção da autonomia ou manutenção da heteronomia entre as crianças. Tal estudo buscou ainda desnaturalizar concepções sobre o que significa uma criança ideal, fácil ou difícil. Foram estabelecidas três categorias comuns às crianças consideradas fáceis e difíceis, quais sejam: aspectos cognitivos; participação da criança; e relacionamento com a professora e com os colegas. Em linhas gerais, os dados mostram que, para a maioria das entrevistadas, um trabalho que privilegia a autonomia é possível com uma criança considerada fácil, porque ela tende a se envolver mais nas decisões do grupo de alunos junto com a professora.

Esses dados evidenciam a noção de que a promoção da autonomia, como princípio, aparece implícita na prática de algumas das professoras, visto que elas tendem a valorizar características tais como o livre-arbítrio e o fato de a criança ser participativa. Logo, a partir da reflexão sobre a veiculação dessas concepções apreendidas e a construção de uma ação pedagógica comprometida com a promoção da autonomia infantil, Almeida e Dessandre (2008) buscaram colaborar, junto aos profissionais de educação infantil, para proporcionar condições favoráveis e desafiantes para o desenvolvimento global da criança, uma vez que são aspectos como esses que estão associados ao papel das concepções sobre o desenvolvimento na construção de um projeto de educação infantil de qualidade.

Buscando também analisar e discutir as concepções sobre desenvolvimento que constituem os saberes e as práticas cotidianas das professoras de educação infantil, Jorge et al. (2008) procuraram verificar, entre 23 professoras da educação infantil, quais eram os objetivos educacionais que as entrevistadas consideravam como prioritários em suas atividades cotidianas e o que gostariam que as suas crianças aprendessem. 
A análise dos dados evidenciou, a partir das falas das entrevistadas, quatro categorias fundamentadas nas seguintes teorias psicológicas do desenvolvimento: a inatista, a ambientalista, a interacionista e a sóciohistórica. Seguida a essa categorização, houve o acréscimo de duas subcategorias: a ambientalista com tendência ao interacionismo e a inatista com tendência ao interacionismo.

Jorge et al. (2008) observaram que as concepções das professoras se pautavam, predominantemente, por uma orientação ambientalista no que se refere aos seus objetivos educacionais, embora existam sinais nítidos, nos seus discursos, de propostas e tentativas de se adotar práticas que valorizem a interação social. Conforme os autores, a considerável ênfase em relação à concepção sócio-histórica por parte das professoras relaciona-se não só com a busca por formação profissional, mas, sobretudo, com a transformação dos seus olhares sobre o mundo, favorecendo a mudança das suas práticas cotidianas.

Por fim, Ramos e Salomão (2013) analisaram as concepções de educadoras em creches públicas sobre o desenvolvimento infantil e sua promoção, buscando, a partir de entrevistas realizadas com 6 educadoras, identificar como as profissionais percebiam aspectos relacionados ao cotidiano das creches, tais como as condições de trabalho e a relação famíliacreche, além das suas concepções sobre o desenvolvimento das crianças com as quais lidavam. Os dados obtidos no estudo demonstraram que as educadoras entrevistadas avaliaram como sendo positivo o desenvolvimento das crianças acompanhadas por elas; e as divergências entre cuidar e educar se apresentaram como parte da rotina de trabalho nas creches, o que terminava por exercer uma influência sobre a relação família-creche. Partindo dessa premissa, Delgado (2015) defende a integração entre cuidados e educação infantil como condição essencial para um atendimento de qualidade à criança, enquanto Vasconcellos (2015) ressalta que a formação do profissional que atua na educação infantil deve se pautar na unificação de atividades de cuidar e de educar que tenham a criança como protagonista de seu processo de aprendizagem e de desenvolvimento.

Conjuntamente, esses estudos evidenciam a relevância de se aprofundar o conhecimento das concepções sobre desenvolvimento infantil de educadores de creche por representarem, entre outros aspectos, formas de se compreender as ações desses profissionais em relação às crianças. 


\section{O estudo}

Configura-se como sendo um estudo qualitativo que procura descrever pormenorizadamente o entendimento dos entrevistados sobre a temática abordada e, por isso, também recorre à quantificação de alguns dados que auxiliam na descrição das frequências das categorias e subcategorias obtidas. Conforme Minayo (2010), a pesquisa do tipo qualitativa possibilita a compreensão de um determinado fenômeno em sua profundidade.

Ressalta-se que o presente estudo foi desenvolvido de acordo com o princípio fundamental de respeito aos aspectos éticos da pesquisa, obedecendo à Resolução 196/96 do Conselho Nacional de Saúde, que assegura os direitos e o bem-estar dos participantes.

\section{Participantes}

Os participantes deste estudo correspondem a 24 educadoras que acompanhavam crianças com idade entre 24 e 30 meses em creches públicas e particulares da cidade de Campina Grande-PB. Esse número de educadoras foi dividido igualmente entre os dois tipos de creche, ou seja, 12 pertencentes às creches públicas e 12 pertencentes às creches particulares. Os participantes foram todos do sexo feminino devido ao fato de não se ter encontrado profissionais da educação do sexo masculino como responsáveis pelas turmas de crianças nesses locais de pesquisa, o que converge com a realidade da maioria das creches e escolas infantis brasileiras.

A idade das educadoras pesquisadas das creches públicas variou entre 22 e 46 anos $(M=33,66)$, e a idade das participantes das creches particulares variou entre 22 e 37 anos $(M=26,58)$. Um total de $83 \%$ das educadoras das creches públicas possuía Nível Superior Completo e as demais (17\%) apresentavam Nível Superior Incompleto, enquanto que o Nível de Escolaridade das educadoras das creches particulares se dividia entre Nível Superior Incompleto (42\%), Nível Superior Completo (33\%) e Nível Médio Completo (25\%).

\section{Instrumentos/procedimentos de coleta e análise dos dados}

A coleta de dados estruturou-se com base na aplicação dos seguintes instrumentos: questionário sociodemográfico e entrevista semiestruturada. 0 
primeiro desses instrumentos caracterizou o grupo de participantes quanto à idade, ao sexo e ao nível de escolaridade. Foi feito um levantamento por frequência desses dados sociodemográficos, os quais serviram para traçar 0 perfil da população pesquisada, conforme descrito no item anterior.

O segundo instrumento, a entrevista semiestruturada, engloba questões elaboradas de acordo com o referencial teórico adotado, com base em estudos na área e no objetivo de investigar as concepções de educadores sobre desenvolvimento infantil. O material coletado com essas entrevistas foi transcrito de forma a preservar a integralidade das falas. Assim, o roteiro de entrevista foi utilizado de maneira a considerar o caráter de espontaneidade da própria entrevista e a liberdade de expressão das participantes, partindo dos seguintes questionamentos: O que é desenvolvimento infantil? Quais os aspectos que você considera que favorecem o desenvolvimento das crianças? E os aspectos que você considera que podem prejudicar o desenvolvimento delas? Para você, como é que o educador pode contribuir para o desenvolvimento das crianças que frequentam a creche?

A análise do material coletado seguiu as três etapas básicas da análise de conteúdo categorial temática (Bardin, 2004), que são: a pré-análise; a exploração do material (recorte e codificação de classes temáticas, categorias e subcategorias); e o tratamento dos resultados (que incluem a inferência e a interpretação). Nessa premissa, foi possível realizar o processo de categorização dos conteúdos das respostas das entrevistadas, considerando a classificação e a agregação das unidades de análise em categorias e subcategorias. Para tanto, utilizou-se a contagem frequencial do número de vezes que, em uma mesma entrevista, determinada categoria ou subcategoria é referida.

\section{Resultados e discussão}

Os dados aqui apresentados resultam da análise e consequente codificação e categorização das respostas das educadoras da rede pública e da rede particular à entrevista semiestruturada. Desse modo, observou-se que essas respostas se distribuíram em três classes temáticas, sendo estas:

1. Concepções das educadoras sobre desenvolvimento infantil: compreende as ideias das educadoras sobre o que vem a ser o 
desenvolvimento infantil. Esta classe temática engloba a categoria Concepções sobre desenvolvimento infantil.

2. Concepções das educadoras sobre os aspectos favoráveis e desfavoráveis à promoção do desenvolvimento infantil: refere-se aos conteúdos que indicam os aspectos considerados pelas educadoras como favoráveis e desfavoráveis para a promoção do desenvolvimento das crianças. Esta classe temática subdivide-se nas categorias: Aspectos favoráveis à promoção do desenvolvimento infantil e Aspectos desfavoráveis à promoção do desenvolvimento infantil.

3. Concepções das educadoras sobre o papel do educador: aborda as concepções que as educadoras apresentam sobre o que vem a ser o papel do educador. Nesse sentido, esta classe temática é representada pela categoria Papel do educador.

Tabela 1, a seguir, apresenta os dados acerca das Concepções das educadoras sobre desenvolvimento infantil.

Tabela 1 - Concepções das educadoras sobre desenvolvimento infantil

\begin{tabular}{cccccccc}
\hline Categoria & Subcategorias & $\begin{array}{c}\text { Educadoras/ } \\
\text { Creches } \\
\text { Públicas }\end{array}$ & $\begin{array}{c}\text { Educadoras/ } \\
\text { Creches } \\
\text { Particulares }\end{array}$ & Total \\
\cline { 2 - 7 } & \multicolumn{1}{c}{$\begin{array}{c}\text { Desenvolvimento por estágios } \\
\text { Desenvolvimento significando um }\end{array}$} & 23 & 28,04 & 20 & 29,44 & 43 & 28,66 \\
\hline $\begin{array}{c}\text { Denjunto de todos os aspectos que } \\
\text { envolvem a criança }\end{array}$ & 18 & 21,95 & 13 & 19,11 & 31 & 20,66 \\
$\begin{array}{c}\text { Concepções } \\
\text { sobre } \\
\text { desenvolvimento } \\
\text { infantil }\end{array}$ & $\begin{array}{c}\text { Desenvolvimento significando } \\
\text { interaçăo }\end{array}$ & 16 & 19,53 & 12 & 17,64 & 28 & 18,66 \\
$\begin{array}{c}\text { Desenvolvimento significando } \\
\text { aprendizagem }\end{array}$ & 12 & 14,63 & 14 & 20,58 & 26 & 17,36 \\
& $\begin{array}{c}\text { Desenvolvimento significando } \\
\text { autonomia da criança }\end{array}$ & 13 & 15,85 & 09 & 13,23 & 22 & 14,66 \\
\hline Total & 82 & 100 & 68 & 100 & 150 & 100 \\
\hline
\end{tabular}

A partir da Tabela 1, verificou-se a predominância, nos dois grupos de educadoras, da subcategoria Desenvolvimento por estágios, visto que ela prevaleceu tanto nas creches públicas ( $f=23 ; 28,04 \%$ ) quanto nas particulares 
$(f=20 ; 29,44 \%)$. Nessa subcategoria, as educadoras destacam a compreensão de desenvolvimento infantil como sendo um processo que ocorre através de estágios evolutivos, como pode ser observado nos trechos de falas a seguir:

Bem, o desenvolvimento infantil eu creio que são as etapas que cada criança vai percorrendo (...). A cada estágio ela vai evoluindo (...). Eu acho que é cada etapa que a criança consegue superar (...). (Creche Pública)

Bem, pra mim, são as etapas pelas quais a criança vai passando, desde pequeninha, bebezinha, quando ela chega aqui bebê, até maiorzinha (...). Então, o desenvolvimento infantil, no caso, seria ela passar as etapas que toda criança passa (...). (Creche Particular)

A partir do conteúdo que emergiu das falas das educadoras entrevistadas no presente estudo, nota-se que seus discursos estão mais orientados por uma visão baseada nos princípios piagetianos de ensinoaprendizagem. Isso leva a inferir que a formação dessas educadoras recebeu, possivelmente, mais influência da teoria piagetina de desenvolvimento humano. É interessante citar que o estudo de Jorge et al. (2008), que buscou discutir as práticas cotidianas e as concepções de desenvolvimento de professoras de educação infantil, apresentou entre suas categorias de análise a concepção interacionista, de base piagetiana, como uma categoria que emergiu das falas das entrevistadas com certo destaque.

No que diz respeito ainda às concepções sobre desenvolvimento infantil, observa-se que a subcategoria Desenvolvimento significando interação aparece como uma concepção intermediária. Essa subcategoria reúne mais aspectos das falas das educadoras sobre as trocas sociais importantes para ocorrerem entre elas e as crianças, por exemplo. Estudiosos, tais como Jorge et al. (2008), Oliveira (2013) e Ramos e Salomão (2013), ponderam que a referência à importância das interações por parte das professoras se relaciona, entre outros aspectos, com a influência mais atual das teorias de caráter sociointeracionista, sobretudo a perspectiva históricocultural de Vigotski (2007), o que termina por ocasionar mudanças na forma como elas compreendem o mundo e a própria criança, além de transformações nas práticas cotidianas.

No que diz respeito às concepções das educadoras sobre os aspectos favoráveis e desfavoráveis à promoção do desenvolvimento infantil, a Tabela 
2, a seguir, evidencia o desdobramento dessas concepções em categorias e subcategorias.

Tabela 2 - Concepções das educadoras sobre os aspectos favoráveis e desfavoráveis à promoção do desenvolvimento infantil

\begin{tabular}{|c|c|c|c|c|c|c|c|}
\hline \multirow[t]{2}{*}{ Categorias } & \multirow[t]{2}{*}{ Subcategorias } & \multicolumn{2}{|c|}{$\begin{array}{l}\text { Educadoras/ } \\
\text { Creches } \\
\text { Públicas }\end{array}$} & \multicolumn{2}{|c|}{$\begin{array}{l}\text { Educadoras/ } \\
\text { Creches } \\
\text { Particulares }\end{array}$} & \multicolumn{2}{|c|}{ Total } \\
\hline & & $f$ & $\%$ & $F$ & $\%$ & $f$ & $\%$ \\
\hline \multirow{5}{*}{$\begin{array}{c}\text { Aspectos favoráveis } \\
\text { à promoçãa do } \\
\text { desenvolvimento } \\
\text { infantil }\end{array}$} & Interação afetiva & 50 & 35,21 & 30 & 36,6 & 80 & 35,71 \\
\hline & $\begin{array}{l}\text { Recursos pedagógicos } \\
\text { diversificados }\end{array}$ & 39 & 27,46 & 14 & 17,07 & 53 & 23,68 \\
\hline & $\begin{array}{l}\text { Conhecimento sobre o } \\
\text { desenvolvimento infantil }\end{array}$ & 21 & 14,78 & 11 & 13,41 & 32 & 14,28 \\
\hline & $\begin{array}{l}\text { Identificaçăo da educadora com } \\
\text { a profissão }\end{array}$ & 20 & 14,1 & 12 & 12,63 & 32 & 14,28 \\
\hline & $\begin{array}{c}\text { Interação com a família da } \\
\text { criança }\end{array}$ & 12 & 8,45 & 15 & 18,29 & 27 & 12,05 \\
\hline \multirow[t]{3}{*}{ Total } & & 142 & 100 & 82 & 100 & 224 & 100 \\
\hline & Despreparo do educador & 20 & 35,1 & 16 & 32,65 & 36 & 33,96 \\
\hline & $\begin{array}{l}\text { Ambiente sociofamiliar } \\
\text { desestruturado }\end{array}$ & 17 & 29,82 & 23 & 46,93 & 40 & 37,73 \\
\hline \multirow{3}{*}{$\begin{array}{c}\text { Aspectos } \\
\text { desfavoráveis à } \\
\text { promoçãao do } \\
\text { desenvolvimento } \\
\text { infantil }\end{array}$} & $\begin{array}{l}\text { Relação creche-família } \\
\text { desfavorável }\end{array}$ & 15 & 26,31 & 0 & 0 & 15 & 14,15 \\
\hline & $\begin{array}{c}\text { Desestímulo às ações das } \\
\text { crianças }\end{array}$ & 0 & 0 & 10 & 20,42 & 10 & 9,43 \\
\hline & Excesso de burocracia & 05 & 8,77 & 0 & 0 & 05 & 4,73 \\
\hline Total & & 57 & 100 & 49 & 100 & 106 & 100 \\
\hline
\end{tabular}

Detendo-se à categoria Aspectos favoráveis à promoção do desenvolvimento infantil, verificou-se que as educadoras das creches públicas e das particulares ressaltaram, em seu discurso, o papel da Interação afetiva ( $f=80 ; 35,71 \%$ para as públicas, $f=30 ; 36,6 \%$ para as privadas) enquanto aspecto importante para o desdobramento desse processo, principalmente no que se refere à questão da convivência entre educadora e crianças, à afetividade e ao saber ouvir, como demonstrado nos trechos de falas a seguir: 
A questão de acolhermos bem, de amar (...). A afetividade do professor, dele com as outras crianças, elas para com o professor (...). Tem que existir uma interação afetiva do professor com o aluno (...). (Creche Pública)

Você tem que conversar e, se ela contar alguma coisa, você tem que ficar empolgado, achar que aquilo ali é a melhor coisa do mundo (...). É a questão da afetividade (...), da interação (...). (Creche Particular)

Ainda no que se refere aos aspectos considerados capazes de promover o desenvolvimento infantil, observa-se que as educadoras das creches públicas salientaram a necessidade de utilizar Recursos pedagógicos diversificados ( $f=39 ; 27,46 \%$ ), enquanto as educadoras das creches particulares enfatizaram a importância da Interação com a família ( $f=15$; $18,29 \%$ ). Esta subcategoria remete às concepções das educadoras sobre a importância da participação da família tanto na vida das crianças em casa quanto no cotidiano da creche.

Conjuntamente, a Interação afetiva, os Recursos pedagógicos diversificados e a Interação com a família são percebidos pelas educadoras dos dois grupos de creches como aspectos que, se presentes nas concepções e práticas dos profissionais da educação infantil, favorecerão a promoção do desenvolvimento das crianças.

Ao investigar sobre os saberes e práticas de professoras da educação infantil, Delgado (2015) defende que o afeto compreende a expressividade e a exteriorização de estados emocionais socialmente elaborados em uma cultura, o que faz dele um regulador das nossas ações. Nessa perspectiva, considera que o professor da educação infantil pode estabelecer relações com as crianças mediante o uso de diferentes canais expressivos e linguísticos, cuja qualidade pode ser potencializada pela presença da afetividade.

Além disso, a Interação afetiva educador-crianças e a Interação com a família são aspectos apontados na literatura como fatores relacionados à satisfação no trabalho como educador (Beraldo \& Carvalho, 2006; Delgado, 2015; Ramos \& Salomão, 2013). Dentre esses estudos, o de Beraldo e Carvalho (2006) destaca os discursos das educadoras sobre o quanto as demonstrações de afeto das crianças tornam significativos os reencontros diários entre crianças e educadoras, resultando na reafirmação do próprio valor e da identidade da educadora, bem como a boa relação com as famílias 
repercute em diversas mudanças positivas no âmbito da creche, gerando uma relação de parceria.

Ademais, Silva e Bolsanello (2002) ponderam que o trabalho na educação infantil exige intervenções planejadas, com organização de espaços adequados e condições para a realização das atividades a serem desenvolvidas com as crianças, o que ressalta, entre outros aspectos, a importância do uso de Recursos pedagógicos diversificados.

Em relação à categoria Aspectos desfavoráveis à promoção do desenvolvimento infantil, observou-se, conforme a Tabela 2, que os dois grupos de educadoras destacaram o impacto negativo do Ambiente sociofamiliar desestruturado, que foi o aspecto mais frequente entre as educadoras das creches particulares $(f=23 ; 46,93 \%)$ e o segundo mais frequente entre as das públicas $(f=17 ; 29,82 \%)$. Exemplos dessas falas podem ser observados a seguir:

Tem a questão social, o meio em que eles vivem, muitas passam necessidades de alimentação (...). Pais que têm problemas em casa e reflete nas crianças (...). A questão da família, das famílias desestruturadas (...). (Creche Pública)

Tem pais que não incentivam a criança a fazer o trabalho, a escrever (...). Eu creio que tem vários aspectos. Seria um deles uma família desestruturada, talvez possa confundir a mente da criança, deixá-la um pouco perturbada, angustiada na sala (...). (Creche Particular)

Nessa mesma perspectiva de discussão, ressalta-se ainda que a subcategoria Relação creche-família desfavorável foi a terceira mais frequente entre as educadoras das creches públicas ( $f=15 ; 26,31 \%$ ), mas não foi mencionada entre as profissionais das creches particulares. Essa subcategoria remete às concepções que as educadoras têm sobre o tipo de relação que há entre creche e família, a qual tem sido vista como uma relação frágil e muitas vezes complicada, como pode ser verificado a seguir:

Eu acho que a falta de relacionamento da família com escola (...). Eu acho que a relação entre família e escola é que vai ajudar, e hoje a gente não vê muito isso (...). A família lá e a escola aqui (...). (Creche Pública)

Diante do exposto, essa prevalência de opiniões, entre as educadoras dos dois grupos de creches (e sobretudo para as educadoras das creches particulares), sobre a questão de o Ambiente sociofamiliar desestruturado representar um aspecto desfavorável à promoção do desenvolvimento infantil 
pode ter relação com o fato de tanto as educadoras das creches públicas quanto das particulares comumente atribuírem aos fatores externos à creche - tais como o ambiente onde as crianças vivem e o tipo de estrutura familiar - a origem dos problemas que prejudicam o desenvolvimento das crianças. Isso parece ter mais ênfase no discurso das educadoras das creches particulares, possivelmente porque elas, ao contrário das educadoras das creches públicas, não fazem referência ao tipo de relação creche-família estabelecida na realidade delas ou, em geral, não expressam se essa relação é delicada ou boa, voltando seu discurso para aspectos como Ambiente sociofamiliar desestruturado.

Nos aspectos considerados desfavoráveis à promoção do desenvolvimento das crianças destacou-se ainda a subcategoria Despreparo do educador, tanto entre as educadoras das creches públicas ( $f=20 ; 35,1 \%)$ quanto entre as das particulares $(f=16 ; 32,65 \%)$, tendo emergido também entre as educadoras das creches particulares a subcategoria Desestímulo às ações das crianças ( $f=10 ; 20,42 \%$ ) como um aspecto a mais que prejudica o desenvolvimento infantil. Observa-se ainda que tem sido, principalmente, a falta de conhecimento sobre desenvolvimento infantil, associada à falta de identificação com a profissão, que tem caracterizado o Despreparo do educador diante do desenvolvimento da criança, como é possível verificar nos trechos de falas abaixo:

A falta de conhecimento dessas etapas do desenvolvimento da criança (...). Muitas vezes, pode partir até de nós educadores mesmo (...). Às vezes, a falta de compromisso (...). Então, o que pode prejudicar é justamente a postura do professor diante da desenvoltura da criança (...). (Creche Pública)

O gritar à criança (...). A forma de você reagir com ela, bruscamente (...). Se o professor não tiver ali do lado, não tiver prestando atenção, não tiver ali acolhendo a criança, vai prejudicar (...). (Creche Particular)

Considera-se pertinente destacar que o aspecto Despreparo do educador tem uma relação com o fato de muitos profissionais da educação infantil não serem preparados para o exercício dessa função. Nesse sentido, Corrêa (2003) considera que, geralmente, as condições de infraestrutura e a formação dos profissionais que trabalham com educação infantil, especialmente em creches, são bastante precárias. Além disso, Oliveira (2001) esclarece que a formação recebida nos cursos de magistério, na maioria das vezes, não prepara os educadores para trabalhar com crianças 
menores de 4 anos, e muito menos para conceber a educação de uma forma ampla em que também estejam inseridos os cuidados biopsicossociais. A partir desse enfoque, Oliveira (2013) destaca a necessidade de se repensar, urgentemente, a formação profissional de todos os que trabalham na educação infantil, pois, para a autora, a inserção da creche no sistema de ensino gerou debates importantes sobre o que significa a formação docente e como preparar profissionais com perfis que respondam mais adequadamente à diversidade de situações presentes na educação infantil.

Por último, destacaram-se as concepções das educadoras sobre o que vem a ser o papel do educador. A Tabela 3 apresenta os dados referentes a essas concepções:

Tabela 3 - Concepções das educadoras sobre o papel do educador

\begin{tabular}{ccccccccc}
\hline \multirow{2}{*}{ Categoria } & Subcategorias & \multicolumn{2}{c}{$\begin{array}{c}\text { Educadoras/ } \\
\text { Creches } \\
\text { Públicas }\end{array}$} & $\begin{array}{c}\text { Educadoras/ } \\
\text { Creches } \\
\text { Particulares }\end{array}$ & Total \\
\cline { 2 - 8 } & $\begin{array}{c}\text { Educar as crianças } \\
\text { Conhecer sobre }\end{array}$ & 19 & 28,35 & 11 & 21,56 & 30 & 25,42 \\
& $\begin{array}{c}\text { Cesenvolvimento infantil } \\
\text { Mapel do educador }\end{array}$ & 17 & 25,4 & 08 & 15,68 & 25 & 21,18 \\
& $\begin{array}{c}\text { Mediar as interações } \\
\text { Estimular o }\end{array}$ & 15 & 22,38 & 08 & 15,68 & 23 & 19,49 \\
& $\begin{array}{c}\text { desenvolvimento infantil } \\
\text { Orientar as famílias }\end{array}$ & 14 & 20,89 & 18 & 35,32 & 32 & 27,11 \\
\hline Total & 02 & 2,98 & 06 & 11,76 & 08 & 6,8 \\
\hline
\end{tabular}

A partir dos resultados expostos na Tabela 3, verifica-se, na categoria Papel do educador, a prevalência das falas das educadoras de creches públicas na subcategoria Educar as crianças ( $f=19 ; 28,35 \%$ ), seguida da subcategoria Conhecer sobre desenvolvimento infantil $(\mathrm{f}=17 ; 25,4 \%)$. As falas a seguir exemplificam esses aspectos:

Como alguém que tem que ensinar alguma coisa pra criança (...). Consegue olhar para cada criança e ver um ser humano também (...). Trazer sempre coisas novas (...). Ser um educador para educar tanto a parte pedagógica como a parte social também (...). (Creche Pública) 
Já nas falas das educadoras das creches particulares, há uma ênfase na subcategoria Estimular o desenvolvimento infantil ( $f=18 ; 35,32 \%)$ como sendo um papel importante a ser desempenhado pelo educador junto às crianças, conforme exemplo de fala a seguir:

Eu acho que incentivando mais ainda (...). Fazendo atividades de acordo com as necessidades de cada um (...). Não entregar a coisa pronta pra criança (...). Eu acho que o educador tem o papel de estimular a criança a se desenvolver (...). (Creche Particular)

Nessa premissa, compreende-se que a inter-relação entre as concepções de desenvolvimento infantil apresentadas pelas educadoras e os aspectos considerados por elas como promotores ou não do desenvolvimento das crianças representa um aspecto que perpassa o que as educadoras concebem como sendo o papel do educador nesse processo. Para Oliveira, Mello, Vitória, e Rossetti-Ferreira (1998), o educador de creche vai se constituir de forma diferente conforme perceba o seu papel na creche junto com as crianças. Assim, poderá se ver como alguém que apenas "cuida" e "toma conta" das crianças ou como alguém que contribui ativamente para o desenvolvimento delas.

Ademais, o fato de as subcategorias Educar as crianças, Conhecer sobre desenvolvimento infantil e Estimular o desenvolvimento infantil terem se destacado no conteúdo das falas das educadoras acerca dos papéis do educador sugere certo entendimento das entrevistadas de que conhecer sobre o desenvolvimento das crianças favorece o uso de estratégias que, de fato, sejam promotoras do desenvolvimento infantil (Seidl-de-Moura et al., 2004).

Nessa premissa, ressalta-se que o conceito de Zona de Desenvolvimento Proximal defendido por Vigotski (2007) tem como principal contribuição a ênfase atribuída ao papel do mediador, cujo suporte é visto como um elemento-chave para o desenvolvimento dos processos de aprendizagem social. Acerca do ambiente escolar infantil, é possível afirmar que as educadoras exercem o importante papel de mediadoras do desenvolvimento proximal das crianças com quem elas interagem, sendo responsáveis, inclusive, por promover situações em que as crianças mais experientes atuam também como facilitadoras do desenvolvimento daquelas que se encontram envoltas em processos de aprendizagem. 


\section{Considerações finais}

O presente estudo possibilitou investigar as concepções de educadoras sobre desenvolvimento infantil em creches públicas e particulares, considerando a ideia de creche enquanto um contexto social que deve ter por objetivo maior a promoção do desenvolvimento das crianças e suas aprendizagens. Nessa perspectiva, entende-se que as concepções das educadoras sobre o que vem a ser o desenvolvimento infantil são relevantes para se buscar compreender a qualidade das estratégias educacionais promovidas por essas profissionais junto às crianças que estão sendo acompanhadas.

Assim, verificou-se que as educadoras, de um modo geral, concebiam o desenvolvimento enquanto um processo composto por etapas pelas quais toda criança passa, sendo compreendido ainda enquanto sinônimo e resultado das interações. Acerca dos principais recursos favoráveis à promoção do desenvolvimento infantil, as profissionais ressaltaram a importância das interações afetivas, dos recursos pedagógicos diversificados e da participação das famílias, ao passo que foram considerados desfavoráveis, justamente, aspectos como o ambiente sociofamiliar desestruturado, a relação creche-família desfavorável e o despreparo do educador, assim como o desestímulo às ações das crianças.

Quanto ao papel do educador, as professoras salientaram a importância de educar as crianças, conhecer sobre o desenvolvimento infantil e estimulá-lo, o que ressalta a noção de que o educador, na condição de mediador, deve ter responsabilidade sobre a qualidade das trocas sociais estabelecidas com as crianças, contribuindo, entre outros aspectos, para a configuração da creche enquanto um contexto de promoção da aprendizagem e do desenvolvimento.

Assim, destaca-se a necessidade de que sejam realizadas investigações futuras concentrando-se, sobretudo, nas análises das relações entre as concepções das educadoras, as teorias sobre desenvolvimento/aprendizagem e as suas ações/estratégias educativas cotidianas, haja vista as possibilidades de contribuição para o planejamento de intervenções e políticas públicas referentes à qualidade das práticas educativas nas creches. 


\section{Referências}

Almeida, F. M. C. \& Dessandre, S. A. B. (2008). Concepções de professoras sobre criança ideal/ fácil/ difícil. In V. M. R. de Vasconcellos, L. M. M. L L. de Aquino \& A. A. Dias (Orgs.), Psicologia e educação infantil (pp. 45-70). Araraquara: Junqueira \& Marin Editores.

Bardin, L. (2004). Análise de conteúdo. Lisboa: Ed. 70.

Beraldo, K. E. A. \& Carvalho, A. M. A. (2006). Ouvindo educadoras de creche sobre suas experiências no trabalho. Temas em Psicologia, 14(1), 35-49.

Corrêa, B. (2003). Considerações sobre qualidade na educação infantil. Cadernos de Pesquisa, 119, 85-112.

Delgado, J. (2015). Entre os saberes e práticas das professoras de educação infantil: Um estudo sobre os cuidados na primeira infância. Poiésis, 9(15), 63-79.

Goodnow, J. J. (1996). From household practices to parents' ideas about work and interpersonal relationships. In S. Harkness \& C. M. Super (Orgs.), Parents' cultural belief systems: Their origins, expressions, and consequences (pp. 169191). New York: The Guilford Press.

Harkness, S., \& Super, C. M. (1996). Parents' cultural belief systems. Their origins, expressions, and consequences. New York: The Guilford Press.

Jorge, A. S., Reis, A. C. \& Nascimento, C. S. P. (2008). Práticas cotidianas e concepções de desenvolvimento de professoras da educação infantil. In V. M. R. de Vasconcellos, L. M. M. L L. de Aquino \& A. A. Dias (Orgs.), Psicologia e educação infantil (pp. 71-93). Araraquara: Junqueira \& Marin Editores.

Melchiori, L. E., Biasoli-Alves, Z. M. M., Souza, D. C. \& Bugliani, M. A. P. (2007). Família e creche: Crenças a respeito de temperamento e desempenho de bebês. Psicologia: Teoria e Pesquisa, 23, 245-252.

Minayo, M. C. de S. (2010). O desafio do conhecimento: pesquisa qualitativa em saúde (12 ${ }^{\mathrm{a}}$ Ed.). São Paulo: Hucitec.

Oliveira, S. (2001). Crenças e valores dos profissionais de creche e a importância da formação continuada na construção de um novo papel junto à criança de 0 a 3 anos. Em Aberto, 16(73), 89-97.

Oliveira, Z. de M. R. de (2013). Educação infantil: Fundamentos e métodos. São Paulo: Cortez.

Oliveira, Z. de M., Mello, A. M., Vitória, T., \& Rossetti-Ferreira, M. C. (1998). Creches: Crianças, faz de conta \& cia. Petrópolis, RJ: Vozes.

Ramos, D. D. \& Salomão N. M. R. (2013). Desenvolvimento infantil: Concepções e práticas de educadoras em creches públicas. Psicologia: Teoria e Prática, 15(3), 200-213.

Seidl-de-Moura, M., Ribas Jr, R., Piccinini, C., Bastos, A., Magalhães, C., Vieira, M., ...Silva, A. (2004). Conhecimento sobre desenvolvimento infantil em mães primíparas de diferentes centros urbanos do Brasil. Estudos de Psicologia, 9, 421-430.

Shawalb, D. W., Shawalb, B. J., \& Shoji, J. (1996). Japanese mothers' ideas about infants and temperament. In S. Harkness \& C. M. Super (Orgs.), Parents' 
cultural belief systems. Their origins, expressions, and consequences (pp. 169191). New York: The Guilford Press.

Silva, C. R. da \& Bolsanello, M. A.(2002). No cotidiano das creches o cuidar e o educar caminham juntos. Interação em Psicologia, 6(1), 31-36.

Vasconcellos, V. (2015). Políticas educativas para crianças de 0 a 3 anos. Fractal: Revista de Psicologia, 27(1), 68-73.

Vigotski, L. S. (2007). A formação social da mente. São Paulo: Martins Fontes. 
CONCEPTIONS ABOUT CHILD DEVELOPMENT IN THE PERSPECTIVE OF EDUCATORS IN PUBLIC AND PRIVATE DAYCARE CENTERS

Abstract

This study aimed to investigate the teachers' conceptions of child development in public and private daycare centers. Therefore, semi structured interviews were applied to 24 teachers. Data were analyzed with the thematic content analysis technique. Generally, it was found that, in what concerns ideas about child development, the subcategory Development by stages predominated in both groups of educators. The teachers highlighted the Unstructured sociofamilial environment and the Unpreparedness of the educators as the main negative points to the promotion of child development and characterized the development of children, when inserted into the routine of the nursery, as positive. With this study we aimed to provide information for planning interventions in order to promote child development.

Keywords

Conceptions; Child development; Educators; Public and private daycare centers

CONCEPCIONES SOBRE EL DESARROLLO INFANTIL EN LA PERSPECTIVA DE EDUCADORAS EN GUARDERÍAS PÚBLICAS Y PRIVADAS

Resumen

En este estudio, se buscó investigar las concepciones de educadoras de guarderías públicas y privadas sobre desarrollo infantil. De ese modo, se aplicó una entrevista semiestructurada a 24 educadoras. Los datos fueron analizados a partir de la técnica de análisis de contenido categorial temático. De modo general, se verificó que, en relación a las concepciones sobre el desarrollo infantil, predominó, en los dos grupos de educadoras, la subclasificación Desarrollo por etapas. Esas educadoras destacaron el Ambiente 
socio-familiar desestructurado y el Despreparo del educador como siendo los principales aspectos desfavorables a la promoción del desarrollo infantil y caracterizan el desarrollo de los niños, cuando inseridos en la rutina de la guardería, como siendo positivo. Nuestro objetivo es, con este estudio, ofrecer subsidios para el planeamiento de intervenciones con vistas a promover el desarrollo infantil.

\section{Palabras-clave}

Concepciones; Desarrollo infantil; Educadoras; Guarderías públicas y privadas

Recebido em junho/2015

Aceite para publicação em setembro/2015

i Departamento de Ciências Humanas e suas Tecnologias, Instituto Federal de Educação, Ciência e Tecnologia da Paraíba, Brasil.

ii Centro de Educação, Universidade Federal de Alagoas, Brasil.

iii Departamento de Psicologia, Núcleo de Pesquisa em Interação Social e Desenvolvimento Infantil, Universidade Federal da Paraíba, Brasil.

Toda a correspondência relativa a este artigo deve ser enviada para: Ellis Regina Ferreira dos Santos, Rua Francisco Alves, $n^{\circ}$ 655, Bairro Presidente Médici, Campina Grande, Paraíba, Brasil, CEP: 58417-603. E-mail: ellisrf@yahoo.com.br 